\title{
SERUM LEVEL OF IL-33 IN GOUTY RENAL PATIENTS
}

\author{
Randa R Mabrouk*, Afaf A Mostafa*, Marwa R El Najjar* and \\ Mariam T Abd El Monaem**
}

\author{
*Department of Clinical Pathology \\ \& Immunology, Ain Shams \\ University \\ ** Resident in the Clinical \\ Pathology department, Nasser \\ Institute for Research, Cairo, Egypt.

\section{Corresponding author} \\ Mariam Tarek Abd El Monaem \\ Mobile: (+2) 01277371137 \\ E.mail: \\ mt.shalaby2016@gmail.com.
}

Received: $18 / 5 / 2021$

Accepted: 9/6/2021

\section{Online ISSN: 2735-3540}

\begin{abstract}
:
Background: Gout is a form of inflammatory arthritis and the most common metabolic disease in humans. It may result in tophi, kidney stones, or even kidney damage. It has become more common in recent decades due to increasing risk factors in the population, such as metabolic syndrome. Interleukin-33, the latest discovery in IL-1 cytokine family, acts as an early alerter of inflammation, it has been linked to several human pathologies including autoimmune diseases, sepsis, and allergy through its specific IL-1 receptor ST2 (suppression of tumorigenicity 2). However, there is little information regarding the role of IL-33 in gout.
\end{abstract}

Aim of the Work: Our study aimed to examine the clinical utility of IL-33 level in serum among gouty patients and correlating its concentration with renal affection.

Patients and Methods: Our case-control study was conducted on 90 subjects divided into three groups. Group I: included thirty gout patients, with no evidence of kidney affection, Group II: included thirty gout patients with kidney affection, their diagnosis based on the American College of Rheumatology classification criteria, Group III: thirty age and sex-matched, apparently healthy subjects included in the study as a control group. All individuals were subjected to detailed medical history, clinical examination including weight measurement and body mass index (BMI), and laboratory parameters including serum uric acid, creatinine, urea, lipid profile, and serum level of IL33 measured by ELISA.

Results: Serum IL-33 was predominantly increased in gout patients (with or without kidney affection) compared to healthy controls and was even higher in patients without kidney injury compared to gout patients with kidney injury. IL-33 was positively correlated with serum HDL, BMI, although it was negatively correlated with LDL and cholesterol.

In Conclusion: IL-33 might have a protective role in kidney injury among gout patients.

Key Words: IL-33, Gout, Kidney affection.

\section{INTRODUCTION:}

Gout is the most common metabolic disease in humans, resulting from purine metabolic disorder in which serum uric acid is above-normal concentrations, associated with deposition in joints and soft tissues causing arthritis, soft tissue masses, nephrolithiasis, and urate nephropathy ${ }^{[1]}$. Over the past several decades, gout prevalence has raised in parallel with current epidemics as type 2 diabetes, hypertension, hyperlipidemia, cardiovascular diseases, renal diseases, and obesity ${ }^{[2]}$. 
Interleukin (IL)-33 is a new member of the IL-1 superfamily of cytokines that are expressed by stromal cells, such as epithelial and endothelial cells, and its expression is up-regulated following pro-inflammatory stimulation ${ }^{[3]}$. IL-33 can function both as a traditional cytokine and as a nuclear factor regulating gene transcription. It is thought to function as an 'alarmin' released following cell necrosis to alert the immune system to tissue damage or stress ${ }^{[4]}$. It mediates its biological effects via interaction with the receptors ST2 (IL-1RL1) and IL-1 receptor accessory protein (IL-1RAcP), both of which are widely expressed, particularly by innate immune cells and T helper 2 (Th2) cells. IL-33 strongly induces Th2 cytokine production from these cells and can promote the pathogenesis of Th2-related diseases such as asthma, atopic dermatitis, and anaphylaxis ${ }^{[5]}$. However, IL-33 has shown various protective effects in cardiovascular diseases such as atherosclerosis, obesity, type 2 diabetes, and cardiac remodeling. Thus, the effects of IL-33 are either pro- or anti-inflammatory depending on the disease and the model ${ }^{[6]}$.

\section{AIM OF THE WORK}

Our study aimed to examine the clinical utility of IL-33 level in serum among gouty patients and correlating its concentration with renal affection. In this study, we focus on the beneficial role of IL-33 in the pathogenesis of gout, through regulating lipid metabolism especially in gouty patients complicated with kidney affection.

\section{PATIENTS AND MATERIALS}

\section{Subjects and sample collection}

The study was conducted in Nasser Institute hospital outpatient \& inpatient clinics. The study included a total of 90 patients divided into three groups. Group I: included thirty gout patients, with no kidney affection (20 males and 10 females, with a mean age of $56.6 \pm 7.3$ years), their serum uric acid was above $(6 \mathrm{mg} / \mathrm{dl})$. Group II: included thirty gout patients with kidney affection (20 males and 10 females with a mean age of $56 \pm 6.4$ years), their serum uric acid were $(>6 \mathrm{mg} / \mathrm{dl})$, blood urea nitrogen (BUN > 20mg/dl) and serum creatinine $(>1.3 \mathrm{mg} / \mathrm{dl}$, unless they were on treatment). Gout patients were diagnosed based on the American College of Rheumatology classification criteria ${ }^{[7]}$. Group III: thirty age and sex-matched, apparently healthy subjects included in the study as a control group (18 males and 12 females with a mean age of 53.6 \pm 6.2 years). Informed consent was taken from all participants and they were subjected to detailed medical history, clinical examination including weight measurement and body mass index estimation, and the laboratory parameters including serum uric acid, serum creatinine, urea, lipid profile, and serum level of IL-33 was measured by ELISA.

Under the complete aseptic technique, five $\mathrm{ml}$ of venous blood were withdrawn after an overnight fast (12-14 hours). Samples were allowed to clot and sera were then separated by centrifugation $(3000 \mathrm{rpm}$, $20 \mathrm{~min}, 25^{\circ} \mathrm{C}$ ) and then divided into 2 aliquots one for measurement of lipid profile and kidney function, while the other aliquot was stored at $\left(-80^{\circ} \mathrm{C}\right)$ until used for IL-33 analysis.

\section{Measurement of serum IL-33:}

IL-33 was measured using Human Interleukin $33 \quad$ Enzyme-Linked Immunosorbent Assay (ELISA) Kit, Cat. No. E0044 Hu, Bioassay Technology Laboratory ${ }^{\circledR}$, CHINA, (218 Ningguo Rd, Yang Pu District, Shanghai 200090, China) according to the manufacturer's protocol.

\section{Measurement of lipid profile \& kidney function:}

Lipid profile and kidney function were measured using VITROS ${ }^{\circledR} 350$, USA. 


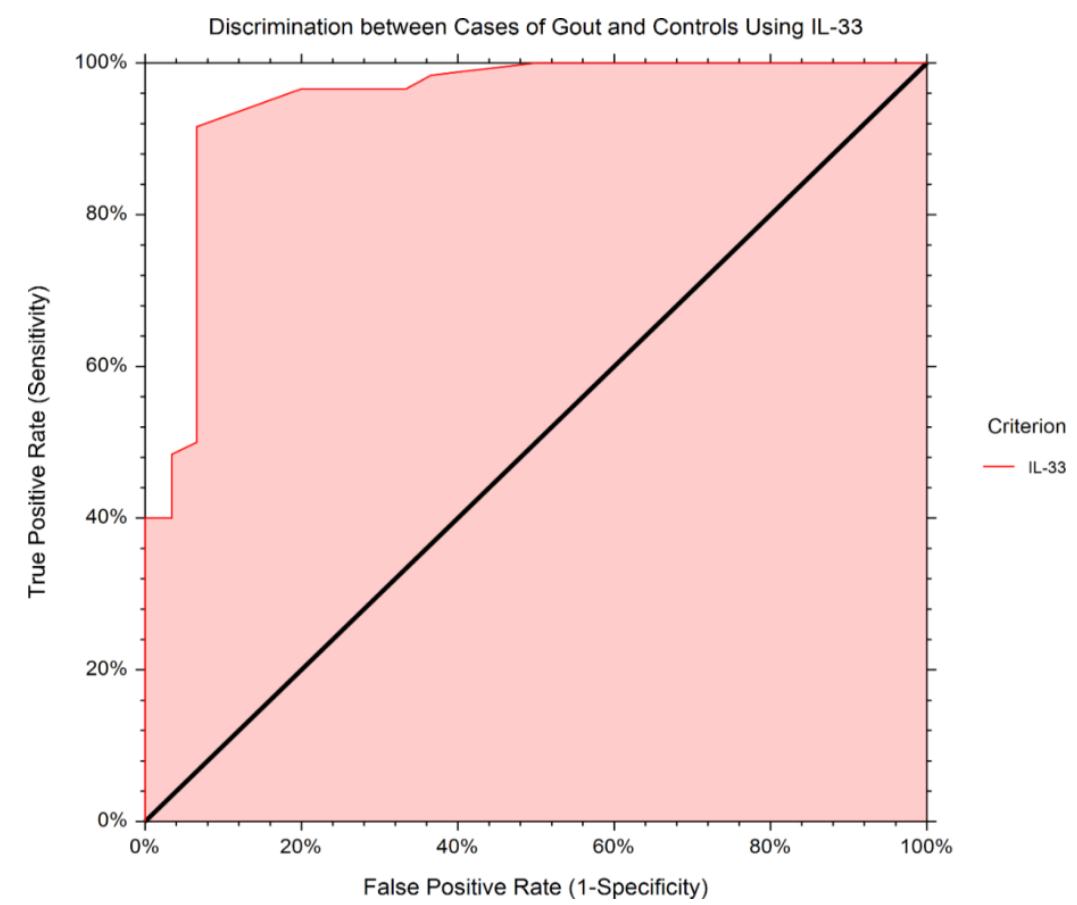

Diagram (1): ROC using IL-33 for discrimination between cases of gout and controls

\section{Statistical analysis:}

Data were analyzed using JMP®, Version 13.2.1(SAS® Institute Inc., Cary, NC). Normally distributed numerical data were presented as mean and standard deviation and intergroup differences were compared using one-way analysis of variance (ANOVA) with an application of the Tukey-Kramer test for post hoc comparison. Non-normally distributed numerical data were presented as median and $25^{\text {th }}-75^{\text {th }}$ percentile and intergroup differences were compared using the Kruskal-Wallis test with the application of the Dunn test for post hoc comparison. Categorical data were presented as ratios and intergroup differences were compared using the Pearson Chi-square test. Correlations were tested using the Spearman rank correlation. The diagnostic value of IL-33 was examined using receiver-operating characteristic (ROC) curve analysis.

\section{RESULTS:}

The comparative statistics of the clinical data showed that there were no statistically significant differences between the three studied groups as regards age and gender $(\mathrm{P}$ $=0.0916$ and $\mathrm{P}=0.824$, respectively).

The serum IL-33 levels in gout patients with or without kidney affection were significantly increased as compared with healthy control $(\mathrm{P}<0.001)$. The median level of IL-33 in gout patients with no kidney affection was $480 \mathrm{pg} / \mathrm{mL}(310-580 \mathrm{pg} / \mathrm{mL})$, in gout patients with kidney affection was $325 \mathrm{pg} / \mathrm{mL}(230-450 \mathrm{pg} / \mathrm{mL})$, while in healthy control was $105 \mathrm{pg} / \mathrm{mL}$ (75-140 $\mathrm{pg} / \mathrm{mL}$ ). While comparison of IL-33 levels between gout patients with and without kidney affection revealed a significant decrease in IL-33 in gout patients with kidney affection than those without kidney affection (Table 1). 
Table (1): Serum IL-33 in the three studied groups:

\begin{tabular}{|c|c|c|c|c|c|c|c|}
\hline \multirow{2}{*}{ Variable } & \multicolumn{2}{|c|}{ Control $(\mathrm{n}=30)$} & \multicolumn{2}{c|}{$\begin{array}{c}\text { Gout with no kidney } \\
\text { affection }(\mathrm{n}=30)\end{array}$} & \multicolumn{2}{c|}{$\begin{array}{c}\text { Gout with kidney } \\
\text { affection }(\mathrm{n}=30)\end{array}$} & \multirow{2}{*}{ p-value* $^{\text {th }}-75^{\text {th }}$} \\
\cline { 2 - 7 } & Median & $\begin{array}{c}25^{\text {th }}-75^{\text {th }} \\
\text { percentile }\end{array}$ & Median & $\begin{array}{c}25^{\text {th }}-75^{\text {th }} \\
\text { percentile }\end{array}$ & Median & $\begin{array}{c}25^{*} \\
\text { percentile }\end{array}$ & $<0.0001$ \\
\hline $\begin{array}{c}\text { IL-33 } \\
(\mathrm{pg} / \mathrm{ml})\end{array}$ & 105 & $75-140$ & $480 \dagger$ & $310-580$ & $325 \dagger \dagger$ & $230-450$ & $<$ \\
\hline
\end{tabular}

*Kruskal-Wallis test.

$\dagger$ p-value $<0.05$ versus Control group (Dunn test).

$\$$ p-value $<0.05$ versus Gout with no kidney affection group (Dunn test).

Using the ROC curve; analysis of IL-33 in discrimination between cases of gout and control at a cut-off level $>150 \mathrm{pg} / \mathrm{mL}$ showed an AUC $=0.949$ and $p<0.0001$. At this cut off, the sensitivity, specificity, PPV and NPV were 91.7\%, 93.3\%, 96.5\% and $84.8 \%$, respectively (Diagram1). On the other hand, ROC curve analysis of IL-33 in discrimination between cases of gout with or without kidney affection showed a cut-off level $\leq 460 \mathrm{pg} / \mathrm{mL}$ with $\mathrm{AUC}=0.680$ and $\mathrm{p}=0.011$. At this cut off the sensitivity, specificity, PPV and NPV were 90\%, 53.3\%, $65.9 \%$ and $84.2 \%$, respectively (Diagram 2 ).

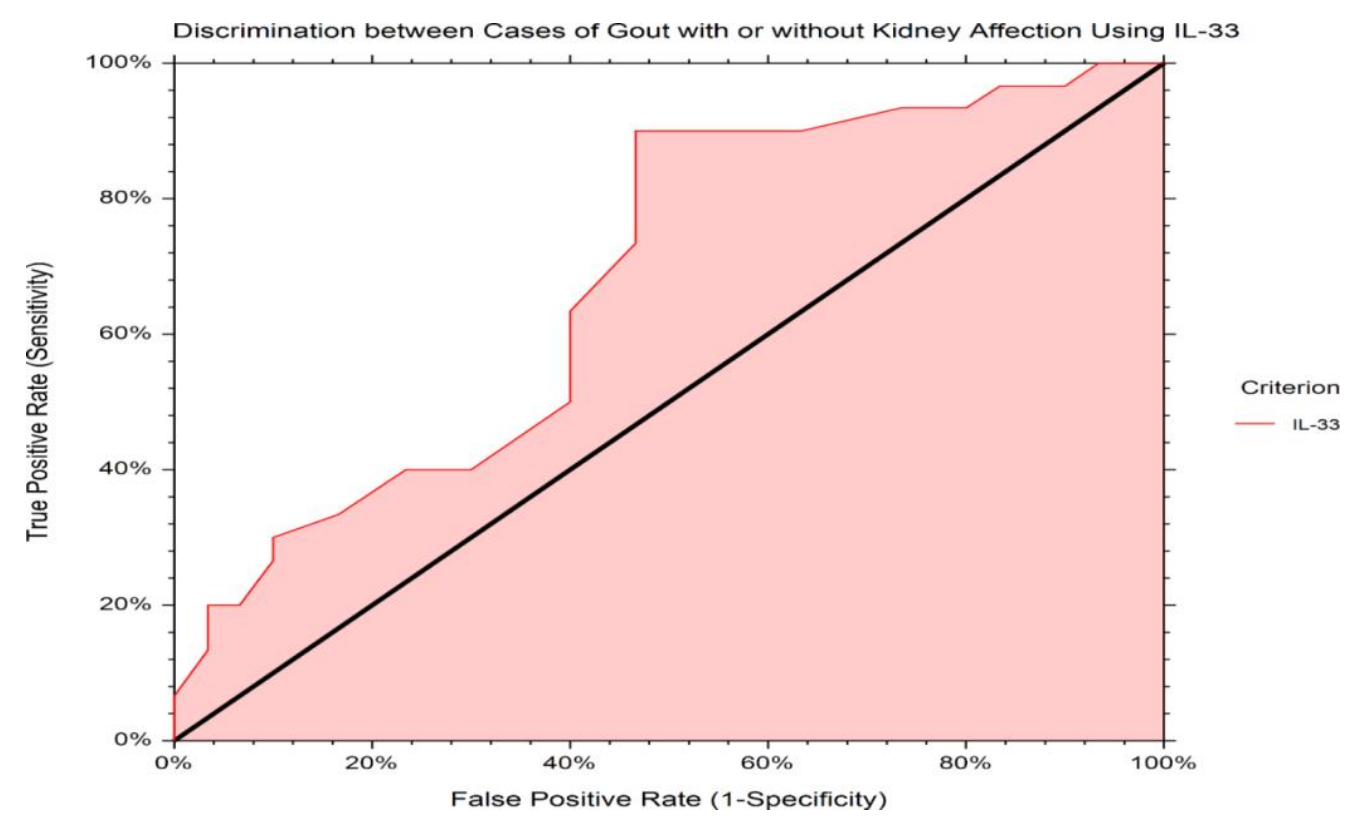

Diagram (2): ROC using IL-33 for discrimination between cases of gout with and without kidney affection

Correlation studies between serum IL33 level and different studied parameters revealed a statistically significant positive correlation between IL-33 and serum HDL in the three studied groups. On the other hand, there was a statistically significant negative correlation between serum IL-33 and serum cholesterol and LDL in the three studied groups. Meanwhile, a highly significant positive correlation with BMI was found only in gout patients with kidney affection and a significant positive correlation with uric acid only in gout patients without kidney affection. There was no significant correlation between serum IL33 level and age, serum creatinine and BUN in the three groups (Table 2). 
Table (2): Correlation between IL-33 and the different parameters in the three studied groups:

\begin{tabular}{|c|c|c|c|c|}
\hline & & \multicolumn{3}{|c|}{ IL-33 } \\
\hline & & Control $(n=30)$ & $\begin{array}{c}\text { Gout with no } \\
\text { kidney affection } \\
(\mathrm{n}=30)\end{array}$ & $\begin{array}{l}\text { Gout with kidney } \\
\text { affection }(n=30)\end{array}$ \\
\hline \multirow{2}{*}{$\begin{array}{c}\text { Age } \\
\text { (years) }\end{array}$} & Rho & 0.257 & 0.144 & 0.273 \\
\hline & p-value & 0.171 & 0.448 & 0.145 \\
\hline \multirow{2}{*}{$\begin{array}{c}\text { BMI } \\
\left(\mathrm{kg} / \mathrm{m}^{2}\right)\end{array}$} & Rho & 0.097 & 0.391 & 0.733 \\
\hline & p-value & 0.611 & 0.088 & $<0.0001$ \\
\hline \multirow{2}{*}{$\begin{array}{c}\text { UA } \\
(\mathrm{mg} / \mathrm{dl})\end{array}$} & Rho & -0.228 & 0.440 & 0.153 \\
\hline & p-value & 0.226 & 0.015 & 0.419 \\
\hline \multirow{2}{*}{$\begin{array}{c}\text { Creatinine } \\
(\mathrm{mg} / \mathrm{dl})\end{array}$} & Rho & 0.267 & -0.079 & 0.120 \\
\hline & p-value & 0.161 & 0.680 & 0.529 \\
\hline \multirow{2}{*}{$\begin{array}{c}\text { BUN } \\
(\mathrm{mg} / \mathrm{dl})\end{array}$} & Rho & 0.278 & -0.114 & -0.036 \\
\hline & p-value & 0.148 & 0.550 & 0.850 \\
\hline \multirow{2}{*}{$\begin{array}{l}\text { Cholesterol } \\
(\mathrm{mg} / \mathrm{dl})\end{array}$} & Rho & -0.552 & -0.775 & -0.716 \\
\hline & p-value & 0.002 & $<0.0001$ & $<0.0001$ \\
\hline \multirow{2}{*}{$\begin{array}{c}\text { HDL } \\
(\mathrm{mg} / \mathrm{dl})\end{array}$} & Rho & 0.922 & 0.882 & 0.750 \\
\hline & p-value & $<0.0001$ & $<0.0001$ & $<0.0001$ \\
\hline \multirow{2}{*}{$\begin{array}{c}\mathrm{LDL} \\
(\mathrm{mg} / \mathrm{dl})\end{array}$} & Rho & -0.436 & -0.728 & -0.787 \\
\hline & p-value & 0.016 & $<0.0001$ & $<0.0001$ \\
\hline
\end{tabular}

rho $=$ Spearman correlation confident, $\mathrm{BMI}=$ body mass index, $\mathrm{UA}=$ uric acid, Creat. $=$ creatinine , Cholest. $=$ cholesterol .

\section{DISCUSSION:}

Interleukin-33, a member of the IL-1 family, is widely expressed in a variety of cells ${ }^{[8]}$. The actions of IL-33 in vivo are pleiotropic ${ }^{[9]}$, it plays dual functions as a nuclear factor or as a cytokine, depending on the various inflammatory environments in different diseases ${ }^{[10]}$. It can act as an endogenous "danger signal" or "alarmin" in order to alert the immune system of tissue damage and infection, and to promote the initiation of a healing response, by promoting alternatively activated macrophage polarization and regulatory $T$ cell differentiation ${ }^{[11]}$. It can also act as a cytokine, as it promotes the polarization of $\mathrm{T}$ cells towards a Th2 cell phenotype and is involved in Th2 type responses through stimulating the production of IL-5, IL-6, IL13 and granulocyte macrophage colony stimulating factor ${ }^{[12]}$. It acts through binding to its receptor, IL-1 receptor-like 1 (IL1RL1) and co-receptor, IL-1 receptor accessory protein (IL-1RAcP) ${ }^{[13]}$.

According to our results, serum IL-33 levels were significantly increased in all gout patients when compared to the healthy control group. This was agreed to results of Duan et al ${ }^{[14]}$ who reported that serum IL33 expression was predominantly increased in gout patients compared to their healthy controls. They supposed that the increased expression of IL-33 in gout patients might be due to self-regulation which inhibits the development of MSU-induced inflammation. However, they stated that the increased amount of IL-33 expression was inadequate to induce a potent protective effect to reduce the development of gout. The authors also added that although endogenous IL-33 does not prevent gout flares, elevated levels may contribute to the resolution of gout flare. IL- 
10 was found to restrain the expression of IL-33 in macrophages and this selectively destroyed the NF- $\kappa B$ signal activated by IL33 and blocked the response of proinflammatory cytokines and chemokines to IL-33, thereby ameliorating the autoimmune arthritis ${ }^{[15]}$. Demirtas et al. ${ }^{[16]}$ claimed that IL-33 might play an important role in the apoptosis- and autophagy-related pathways of nephropathy. Autophagy activated via IL33 may be cytoprotective in CKD. Hence, activation of IL-33 might provide a therapeutic rationale in CKD patients.

In contrast to our results, another study was done by Ferhat et al. ${ }^{[17]}$ in to compare the serum concentrations of IL-33 and its receptor [suppression of tumorigenicity 2 (sST2)] between patients with CKD and healthy individuals. Their results showed no difference in the serum concentration of IL33 between the patients and healthy individuals, whereas a higher serum level of the sST2 was found in the CKD patients with a significant correlation between the serum level of sST2 and disease severity. The authors proposed that endogenous IL-33 is released as an alarmin and contributes to kidney ischemia-reperfusion injury (IRI) by promoting invariant natural killer T (iNKT) cell recruitment and cytokine production which results in neutrophil infiltration and activation at the injury site. Also, a study done by Bao et al ${ }^{[18]}$ reported that IL-33 levels did not differ between patients with CKD and healthy individuals and that IL-33 levels are similar in all the stages of kidney injury when the patients are divided into groups according to their GFR. Musolino and his colleagues ${ }^{[19]}$ reported that IL-33 levels did not differ between multiple myeloma patients with and without kidney failure. Caner S. et al ${ }^{[20]}$ in their study reported that the increase in IL-33 levels in their diabetic nephropathy patients is not associated with kidney injury but the increase could be because of diabetes itself. The discrepancy between our results and others may be due to other pathological factors independent from kidney injury.

Furthermore, we observed that among our gout patients, those with kidney affection showed lower IL-33 levels when compared with those without kidney affection. Duan et al. ${ }^{[14]}$ have shown that in patients with gout nephropathy the expression of IL-33 was markedly higher in patients without kidney damage. IL-33 levels decrease as blood creatinine increases. They found that as IL-33 decreases, HDL also decreases which is similar to our results. Our study showed that serum levels of IL-33 were positively correlated with HDL in gout patients. Also, serum IL-33 levels showed an inverse correlation with creatinine and urea in these patients. IL-33 is a potent inhibitor of macrophage foam cell formation in vivo and in vitro and attenuates atherosclerosis as it blocks foam cell formation by directly regulating the expression of genes for acetyl LDL (AcLDL)/oxidized low density lipoproteins (OxLDL) uptake, storage of cholesterol esters and triglycerides, cholesterol efflux/transport and by inducing a phenotypical Th1-to-Th2 switch ${ }^{[21]}$. These findings could be explained by the fact that IL-33 might play a protective role in the kidney injury of gout through regulating lipid metabolism.

In pursuing the pharmacological potential of IL-33/ST2, it is important to acknowledge the detrimental versus protective effects of IL-33/ST2 signaling. The results presented in our work suggested that the serum IL-33 could be a sensitive marker for kidney function in gout patients. However, further studies are required to explore the specific regulation mechanism between IL-33 and renal function, and to clarify the value of IL-33 in all stages of kidney injury. A correlation between serum and urinary levels of IL-33 can be of value.

In conclusion, IL-33 serves as an important local link between tissue injury or metabolic disturbances and a physiological 
response of limiting or repairing tissue damage. These data may further suggest a novel approach in treating gouty arthritis. A cellular or targeted approach is needed to exploit the beneficial therapeutic potential of IL-33.

\section{REFERENCES}

1. Qing Y.F., Zhang Q.B., Zhou J.G. \& Jiang L. (2014): Changes in toll-like receptor (TLR) 4-NFKB-IL1 $\beta$ signaling in male gout patients might be involved in the pathogenesis of primary gouty arthritis. Rheumatol. Int.; 34: 213.

2. Thottam G.E., Krasnokutsky S. \& Pillinger M.H. (2017): Gout and metabolic syndrome: a tangled web. Current Rheumatology Reports; 19(10): 60.

3. Fang Y., Li W., Xu H., Mao J. \& Shang S. (2019): Association between Interleukin-33 Polymorphism and Henoch-Schönlein Purpura in Chinese Children. Iranian Journal of Pediatrics; 29 (1).

4. Louten J., Rankin A.L., Li Y., Murphy E.E. \& de Waal Malefyt R. (2011): Endogenous IL-33 enhances Th2 cytokine production and T-cell responses during allergic airway inflammation. International Immunology; 23(5): 307.

5. Bartemes K.R., Iijima K., Kobayashi T., Kephart G.M. \& Kita H. (2012): IL-33responsive lineage- $\mathrm{CD} 25+\mathrm{CD} 44^{\mathrm{hi}}$ lymphoid cells mediate innate type 2 immunity and allergic inflammation in the lungs. The Journal of Immunology; 188(3): 1503.

6. Miller A.M. (2011): Role of IL-33 in inflammation and disease. Journal of inflammation; 8(1): 1 .

7. Wallace S.L., Robinson H., Masi A.T., Decker J.L. \& Yü T.S.F. (1977): Preliminary criteria for the classification of the acute arthritis of primary gout. Arthritis \& Rheumatism; 20(3): 895.

8. Moussion C., Ortega N. \& Girard J.P. (2008): The IL-1-like cytokine IL-33 is constitutively expressed in the nucleus of endothelial cells and epithelial cells in vivo: A novel 'alarmin'. PLoS One; 3(10): 3331.

9. Alvarez F., Fritz J.H. \& Piccirillo C.A. (2019): Pleiotropic effects of IL-33 on CD4+T cell differentiation and effector functions. Frontiers in Immunology; 10: 522.

10. Cayrol C. \& Girard J.P. (2018): Interleukin33 (IL-33): a nuclear cytokine from the IL-1 family. Immunological Reviews; 281(1): 154.

11. Bianchi M.E. (2007): DAMPs, PAMPs and alarmins: All we need to know about danger. J. Leukoc. Biol.; 81: 1.

12. Smithgall M.D., Comeau M.R., Yoon B.R., Kaufman D., Armitage R. \& Smith D.E. (2008): IL-33 amplifies both Th1- and Th2type responses through its activity on human basophils, allergen-reactive Th2 cells, iNKT and NK cells. Int. Immunol.; 20: 1019 .

13. Martin M.U. (2013): Special aspects of interleukin-33 and the IL-33 receptor complex. Semin. Immunol.; 25:449.

14. Duan L., Huang Y., Su Q., Lin Q., Liu W ., Luo J., Yu B., He Y., Qian H., Liu Y. \& Chen J. (2016): Potential of IL-33 for preventing the kidney injury via regulating the lipid metabolism in gout patients. Journal of Diabetes Research; 2016: 1028401.

15. Wu M., Tian Y., Wang Q. \& Guo C. (2020): Gout: a disease involved with complicated immunoinflammatory responses: a narrative review. Clinical Rheumatology; 39: 2849.

16. Demirtas L., Turkmen K., Kandemir F. M., Ozkaraca M., Kucukler S., Gürbüzel M., \& Comaklı S. (2016): The possible role of interleukin-33 as a new player in the pathogenesis of contrast-induced nephropathy in diabetic rats. Renal Failure; 38 (6): 952.

17. Ferhat M., Robin A., Giraud S., Sena S., Goujon J.M. \& Thierry A. (2018): Endogenous IL-33 contributes to kidney ischemia-reperfusion injury as an 


\section{Randa R Mabrouk, et al.,}

alarmin. Journal of the American Society of Nephrology; 29(4): 1272.

18. Bao Y.S., Na S.P., Zhang P., Jia X.B., Liu R.C., Yu C.Y. \& Xie R. J. (2012): Characterization of interleukin-33 and soluble ST2 in serum and their association with disease severity in patients with chronic kidney disease. Journal of Clinical Immunology; 32(3): 587.

19. Musolino C., Allegra A., Profita M., Alonci A., Saitta S., Russo S. \& Gangemi S. (2013): Reduced IL-33 plasma levels in multiple myeloma patients are associated $\begin{array}{lcc}\text { with more } & \text { advanced stage } & \text { of } \\ \text { disease. British } & \text { Journal } & \text { of }\end{array}$ Haematology; 160(5): 709.

20. Caner S., Usluoğulları C.A., Balkan F., Büyükcam F., Kaya C., Saçıkara M. \& Çakır B. (2014): Is IL-33 useful to detect early stage of renal failure? Renal Failure; 36(1): 78.

21. McLaren J.E., Michael D.R., Salter R.C., Ashlin T.G., Calder C.J., Miller A.M. \& Ramji D.P. (2010): IL-33 reduces macrophage foam cell formation. The Journal of Immunology; 185(2): 1222.

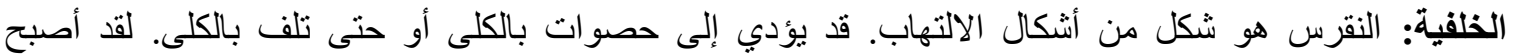

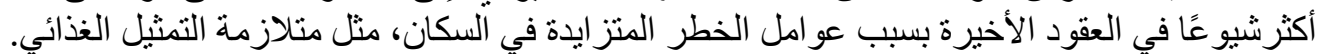

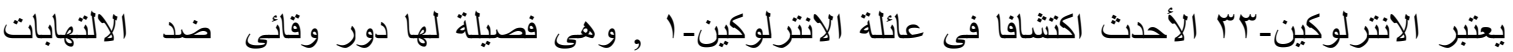

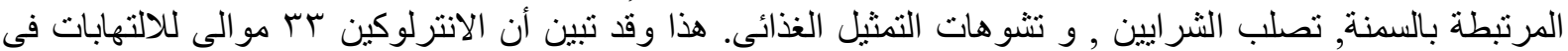

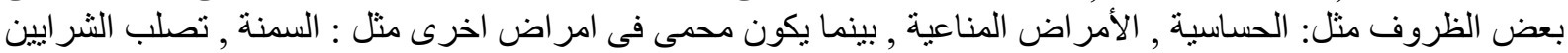

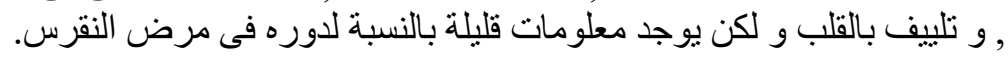

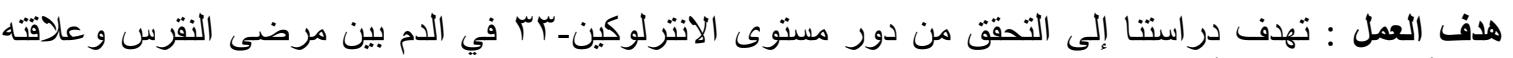

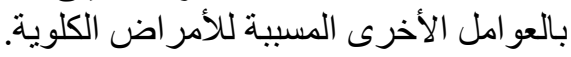

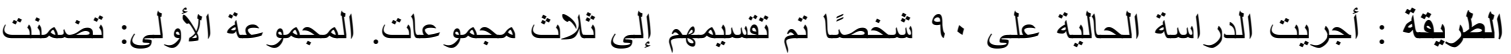

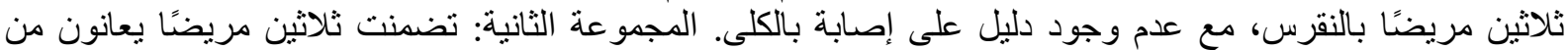

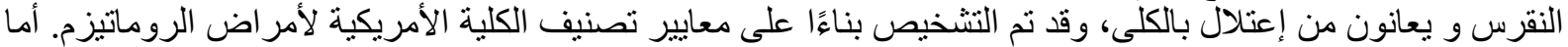

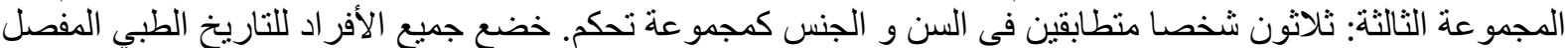

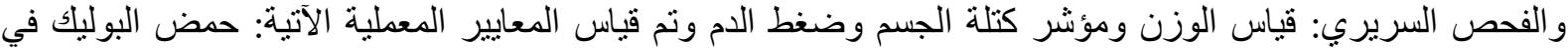

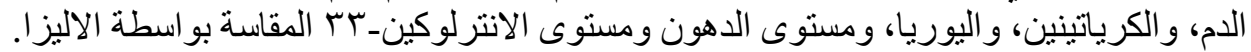

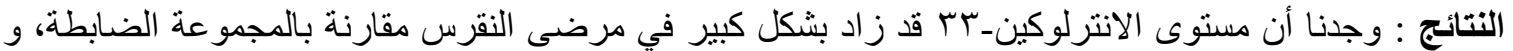

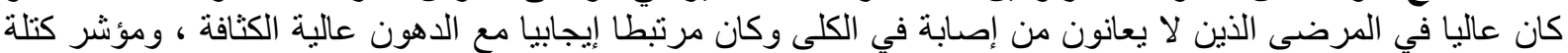

في الختام : قد يكون الانترلوكين_س دور وقائي في إصابة الكلى بين مرضى النقرس.
} 